\title{
The role of comprehensive international electronic medical file in improving the quality of medical services and achieving the satisfaction of stakeholders: An exploratory study in Jeddah, Saudi Arabia
}

\author{
Nayef Al-Ghamri* \\ Department of Human Resources, Faculty of Economics and Administration, King Abdulaziz University, Jeddah, Saudi Arabia
}

Received: June 17, 2021

DOI: $10.5430 /$ jha.v10n4p15
Accepted: July 14, 2021

Online Published: July 23, 2021

\begin{abstract}
Objective: The current study investigates the possible impact of creating a comprehensive international electronic medical file that is part of a database which can be used in various areas to achieve the highest levels of satisfaction for patients and official bodies and enhance the quality of medical services at hospitals as well. One of the key purposes of this e-file is achieving the readiness and confidentiality of data so that it can be shared among hospitals whether inside the Kingdom of Saudi Arabia or even abroad. In addition, the medical e-file may contribute to reducing the costs of treatment, monitoring the performance of doctors and minimising medical errors. Moreover, the e-file may be used for even other purposes such as security or financial reasons. Methods: The study employed the quantitative research design where 171 questionnaires were distributed to patients, managers and staff in 19 small private hospitals in Jeddah city. The questionnaire 44 questions were designed after conducting a small pilot study on 15 participants. The response rate was about $82.5 \%$ in terms of the study questionnaire as only 141 questionnaires were collected. 84 male and 57 female participants took part in the study.

Results: The study shows that there is a statistically significant correlation between the use of the international electronic medical file and the enhancement of the quality level of services provided at hospitals, the electronic rehabilitation, training, integrity and awareness of medical staff, and the productivity of hospital workers in line with the Kingdom's 2030 vision. Moreover, there is a statistically significant correlation between the use of the comprehensive international electronic medical file and raising the level of patient satisfaction by working to protect their medical and financial information and speeding up the process of providing it whenever needed, whether inside the KSA or abroad, as well as reducing the costs of treatment locally and internationally and raising the rates of patient awareness of their medical rights. The results also reveal that using the comprehensive international electronic medical file helps to link patients' data to all concerned authorities, which leads to enabling them to monitor the performance of hospitals and their staff, monitor the performance of doctors, reduce medical errors, and follow up on patients' cases and rights to the fullest extent.

Conclusions: The study recommends the necessity of selecting and training medical personnel in a professional manner, including those working in the field of the database, and the necessity of maintaining the confidentiality of personal information.
\end{abstract}

Key Words: Electronic file, Hospitals, Satisfaction, Performance, Quality of services, Official bodies, Saudi Arabia

\footnotetext{
*Correspondence: Nayef Al-Ghamri; Email: nayef.alghamri@gmail.com; Address: Department of Human Resources, Faculty of Economics and Administration, King Abdulaziz University, Jeddah, Saudi Arabia.
} 


\section{INTRODUCTION}

The technological revolution, or what is known as the third industrial revolution, has contributed to achieving a qualitative leap in the lifestyle as a whole, and the Internet has become the oxygen for many people and transformed the traditional life of individuals into a digital life that interfered in all areas of society from health to education. Technology nowadays is the backbone of all services and production facilities. Besides, it has much contributed to providing data for individuals and companies. Hospitals have benefited from information technology as well through the electronic medical file, but its use is centered only inside the hospital and between the doctors and the hospital administration.

The importance of the research appears at the first place due to the scarcity of research that dealt with the comprehensive electronic medical file which is much needed in small hospitals as a means and not an end. This study can be considered as one of the few studies that dealt with this topic from all aspects in terms of security culture, individual awareness, enhancing the level of quality of the provided services, achieving the satisfaction of all stakeholders including patients and public authorities, and creating an appropriate environment which contribute to increasing productivity and reducing costs. ${ }^{[1]}$ The topic was not given adequate time, effort or attention among researchers in the field of medical science management.

Furthermore, it is worth noting that fighting against medical errors, achieving the patient satisfaction and working on enhancing medical services in hospitals add to the significance of the research as it assumes a positive correlation with developing and improving the quality of services through modern methods and technologies. ${ }^{[2]}$ If the results and recommendations of this research are considered, not only patients will be benefitted but also business owners, staff working in these projects, and the official authorities represented in hospital-related entities such as insurance companies and other authorities will find it very useful. However, technological development and internal and external environmental changes have placed many burdens and responsibilities on the shoulders of hospitals, especially the small ones, but assuming these responsibilities brings them competitive advantages. ${ }^{[3]}$

In the same vein, the success of the medical e-file programs is not limited to small hospitals in terms of treatment costs and wasted time, but may rather lead to enhancing the productivity of doctors. For example, the doctor can benefit from the experiences of local and international doctors who treated this patient as all medical records are available. The patient satisfaction may be affected as well, as the e-file may make it unnecessary for him to redo medical examinations, which saves effort, time, and money.

Therefore, there is a bad need to create an electronic medical file, protect its data, and control health information in all hospitals. Accordingly, the problem appears in the lack of an information and resources among the owners of small hospitals about the comprehensive electronic medical file and the lack of awareness of medical and other security personnel of its importance.

Thus, this research attempts to answer the following questions:

(1) To which extent can the international electronic medical file enhance the quality of medical services?

(2) To which extent can the international electronic medical file help achieve patient satisfaction?

(3)How far is the international electronic medical file able to achieve satisfaction of the official bodies?

\subsection{Hypotheses}

There is a positive correlation between the comprehensive electronic medical file and the following:

(1) Readiness, speed and confidentiality of the information and data provided to the patient.

(2) The availability of medical information for doctors inside and outside the Kingdom of Saudi Arabia.

(3) The reduction of treatment costs in case the patient seeks treatment internationally, which contributes to achieving patient satisfaction.

(4) The patient's awareness of his legal rights.

(5) Observing doctor's performance and the minimizing medical errors.

(6) Benefiting from the international competition among hospitals in improving the quality of doctors' and hospitals' performance.

(7) The penetration of medical files of the elderly.

(8) The readiness of medical information and linking it to other official bodies.

\section{THEORETICAL BACKGROUND AND RE- VIEW OF LITERATURE}

The comprehensive international electronic medical file attracted a growing interest and in part stimulated a debate among those involved in a way or another in the medical field. The e-file, broadly speaking, is an electronic form of medical record which can provide all the information per- 
taining to a patient in one place. It may provide detailed information for different stakeholders including but not limited to the patients, doctors and medical institutions such as other authorities and official bodies.

\subsection{Medical errors and the e-file role}

Medical errors may happen for many reasons and the emedical file can help minimize them. ${ }^{[4]}$ They may occur due to improper examination of the patient or lack of ability to evaluate his condition well. They may also happen due to lack of consent from the patient for any medical procedures or failure to clarify the situation for the patient or the dispersion of the patient in follow-up at different places of treatment with many specialists. When a patient is followed up by several doctors in a number of hospitals or medical centers, and there is no electronic medical file for him showing his condition or the medications given to him, the patient may be given medications that may conflict with each other, leading to negative and undesirable consequences. The e-medical file can minimize errors pertaining to communication and information transfer, such as dispensing a medicine instead of another similar one by name, giving a double dose due to blurred handwriting, mixing files due to similarity of patients' names, or incorrect diagnosis based on the result of wrong tests or tests registered in the name of another patient.

In addition, other medical errors may take place due to failure to record the patient's medical history or medications used in the patient's file, or failure to record the types of allergies that the patient suffers from. For example, in the absence of a health sector worker and the assignment of his duties to his representative, it may lead to many medical errors or negligence on the part of the nurse, as happens in the delivery of the oxygen tube, which leads to complications that may lead to clinical death. Furthermore, there are other technical errors that may occur when wrong labeling happens for a medication container or when putting a different blood type on the blood bag. Equipment failure such as a malfunction of the venous pump which may result in an over or under dose of treatment which may cause a serious issue.

It is pointed out that wrong diagnosis may happen due to an error in the tests or medical procedures. ${ }^{[5]}$ In addition, medical errors may occur as a result of dispensing counterfeit medicines from an unauthorized doctor or a pharmacy, as 60 percent of counterfeit medicines are consumed in poor countries and most of them are sold via the Internet. Unfortunately, the sales value of counterfeit medicines exceeded 75 billion dollars in 2010. ${ }^{[6]}$

Even the building design can stand behind some of the medical errors as a defect in the architectural design of the health building, such as the absence of fire alarms or emergency exits. Another example is the lack of supporting bars in toilets to help patients move, which may cause them to fall down. As for the economic problems due to medical errors, they may appear in the withdrawal of some clinics or hospitals from the market and the layoff of their employees as a result of the decline in their profits or their bankruptcy.

\subsection{Infectious diseases and the e-file role}

Talking about infectious diseases at the time of Corona Virus seems cushy as almost everyone has either a personal experience or one in the closest circle of his immediate relations. At the pandemic times, health data and time maximize in importance to save lives when people and doctors are hit by any of the infectious diseases that are transmitted through viruses and microbes or their association with the patients, such as immunodeficiency diseases, tuberculosis, Covid 19, and infectious diseases that affect animals and birds (SARS, bird flu), which may cause permanent disability for some medical workers. ${ }^{[7]}$

Moreover, there are other diseases that appear due to Covid 19 as a result of a weak immune system of the individual, such as black fungus. It appeared in India as a result of Corona patients' use of cortisone in large quantities and without consulting doctors, or their use of unsterilized oxygen tubes contaminated with black fungus, or the lack of cleanliness of vegetables and food. One of its causes is an increase in iron in the blood as a result of infection with Corona and the severe shortage of white blood cells along with AIDS infection. Black fungus appears among workers in agriculture, soil, and construction workers and its death rate reaches fifty percent. ${ }^{[8]}$ Some of the main reasons that contribute to its spread are the lack of hygiene, lack of medical awareness, and people group housing. What makes it even worse is the cost of treatment, which reaches 2,700 dollars, as the patient needs an injection of (Info-B) every day for eight weeks, and the value of one injection is 48 dollars. This price is unaffordable for some patients. Let alone the lack of the medication and the need to purchase it from the black market at exorbitant prices.

The medical file contributes to preventing the spread of infectious diseases by spreading the culture of health awareness among medical workers and patients. It can serve as an accurate record for vaccinations against infectious diseases and can provide precious data for treating chronic cases, follow up on cases of infectious diseases, monitor the places of their spread such as old and crowded neighborhoods and population gatherings such as workers' and students' housing, which may make the spread of such diseases easier between them and any group of individuals in cities and villages. 
The e-medical file may play the role of life saver in cases of need to communicate patients' data among hospitals or doctors locally or even internationally and prevent or control the transmission of the infection from place to place.

\subsection{Medical e-file role in serving the official authorities and achieving their satisfaction}

The electronic medical file is meant to serve may official authorities for various reasons containing data that could be of interest to many of them for different reasons such as the following:

- International and local hospitals to view the patient's file, the tests they performed, and the medicines they consumed.

- Insurance companies to know the person's age, violations and health aspects.

- Pharmacies in the case of dispensing medicine from outside the hospital to know the original medicines from the counterfeit medicines and their source. It is sometimes difficult to detect fraudulent medicines because they need trained staff. Unfortunately, due to their huge profits, many drug dealers have turned to work in the counterfeit medicine trade, where the laws of punishment are much more lenient than the laws of drugs. This is of much importance because some patients especially in poor countries due to the high prices of original medicines, may accept counterfeit medicines due to their cheap prices. ${ }^{[5]}$

- Retirement Authority to obtain a statement of treatment and dispense free medicines and discounted tickets.

- The Ministry of Health to know the performance of hospitals, the trust of doctors, the process of dispensing the medicine, the number of medicines dispensed, their effects on the patient's health and their compatibility with other diseases such as heart diseases, as some medicines may cause fatal problems for heart patients. The Ministry of Health may need also to know about the required examinations, the costs of these examinations, the reality of the patient's need for them, the degree of follow-up of the patient by the doctor, medical errors and complaints submitted by the auditors, and their views on the medical services provided. The Ministry of Health is meant to be the supervisor of the comprehensive medical file.

- Civil Affairs Authority to issue identity cards getting data about blood type, fingerprint, personal photos and special needs.

- Banks loan management to know about the health history of the loan applicant.

- Universities, institutes and schools to know the health history of students.

- The Association of Physicians for the Elderly to identify critical and emergency cases and link them to a hand watch to monitor the condition of the heart, blood sugar and other health conditions of the patient, provided that all information is recorded directly to the person's file electronically. ${ }^{[9]}$

- Internal and External Scholarships Authority to know students' and employees' places of residence and their health status, and for the health and educational investigator to have the ability to view the scholarship file to know their health status and to reach an understanding with hospitals to approve the financial disbursement.

- Police and public security to get the needed data in case of investigating a crime or solving a security mystery that information about specific doubted persons may prove or negate their connection to the crime in no time.

- Traffic Authority to find out the violations, the health and criminal status and the address of the concerned persons.

\subsection{Previous studies}

The previous related studies focused on the importance of implementing the medical file and the interest of hospitals' management to follow up on their employees and enhance their awareness and cultural level. ${ }^{[10]}$ However, these studies did not address thoroughly the rights of patients or the international medical e-file that crosses the boarders of countries. Some other western studies focused on evaluating the results achieved by the medical file programs in achieving job satisfaction, reducing costs, reducing work turnover, and raising the morale of employees. ${ }^{[11]}$ As for the current study, it came to be more comprehensive, as it paid attention to all factors affecting patient satisfaction and improving the quality of medical services at hospitals from the material, moral and societal aspects. It dealt with the patient's culture, rights, doctor's ethics, and working on establishing an international medical e-file that contributes to reducing re-examination expenses, speeds up the treatment procedures, and achieves readiness and confidentiality of information. This e-file is expected to become a personal file that contains educational, medical and even security information and database that enables the person to use this information at anytime and anywhere and the concerned authorities can also make use of such data especially at the time of a pandemic such as the Corona Virus era that we are living right now. Such pandemic periods show clearly the importance of having such information available for different stakeholders for the sake of the safety not only of the community but also the world as a whole.

In Saudi Arabia, Al-Shehri shed light on the extent to which information systems were activated in the health system in the country and how they were employed effectively. ${ }^{[12]} 48$ participants were interviewed and it was concluded that using health information systems in hospitals in Riyadh was 
not particularly effective in electronic file exchange services inside and outside the hospital, and the most used messaging system in these hospitals was the e-mail. It was also concluded that among the weaknesses of information systems in the health strategy that negatively affected the level of health security in the Kingdom was the difficulty of linking military and government hospitals with a unified information system. Besides, there was a lack of availability of accurate health data, and a quantitative and qualitative shortage of qualified technical human cadres in the field of information technology.

In the same vein, there was an attempt to evaluate the quality of the documentation process in terms of the electronic medical records and collect the doctors' feedback on the obstacles and the factors that facilitated the effective functioning of the system. ${ }^{[13]}$ The researchers collected data from 7 units chosen randomly from each administrative region, and each unit had 50 paper records with the corresponding electronic records chosen. Administrative data were nearly complete in both paper and electronic records. The accuracy rate in the main diagnosis of the electronic records compared to the paper records ranged between $44 \%$ and $82 \%$. On the other hand, the obstacles that were mentioned as impeding the electronic records system were the heavy workload and the complexity of the system.

As a follow up and echoing for what Noureldin and colleagues $^{[13]}$ concluded, Al-Qassem ${ }^{[14]}$ aimed to figure out the reality, impact, and requirements of implementing electronic management on the development of medical services. The study recommended, based on the data collected from 113 surveys, that the administration in the higher leadership should be urged to continuously strive to modernize and develop the electronic abilities in medical services, involve the administrative levels in the transformation process, and train their human resources.

Another aspect, which is not less important than the ones discussed in the earlier studies, was tackled by Al-Sudairi. ${ }^{[15]}$ His study focused on the security factor which cannot be neglected whenever discussing any electronic systems. The study gathered data via 83 surveys and found out that although the communication and information equipment and technologies are in secure rooms that only authorized persons can access, and there is a proper use of secure terminals in the vital sites of the hospital, there are some challenges that may limit the role of communication and information security departments in facing the breaches of military hospital systems in Riyadh that are represented, to a large extent, in the absence of a clear strategy to confront the breaches of military hospital systems. The study stressed the impor- tance of attaining high levels of information security and recommended developing a sustainable strategy to maintain the security of communications and information in military hospitals and conducting periodic testing of information and communication systems to ensure their safety from exposure to penetration, encroachment, interference and eavesdropping. Besides, it referred to the necessity of paying attention to training and qualifying the human and technical cadres, and providing the necessary financial resources to protect the communication and information security in hospitals.

The medical model of Al-Sulami ${ }^{[16]}$ showed the same failure of hospital systems to be linked to each other and the lack of recognition of the deaths of unknown persons, which had a negative impact on the performance of the hospitals and doctors, and increased the dissatisfaction of the relatives of the dead as well. The study gathered data via 150 surveys and concluded the need to standardize medical data so that it contains fingerprint records linked to the Absher system, ID number and passport, which helps in identifying the person in cases of death, disasters, fires, etc.

In the same vein, Al-Waala ${ }^{[17]}$ aimed to identify the reality of the implementation of electronic management in the Kingdom of Saudi Arabia and the implications of the implementation of electronic management on the development of administrative work and the provision of health services. Moreover, the study targeted clarifying the role of electronic management in cases of enhancing health security.

In full harmony with the results of the previously mentioned studies, it was concluded that there was a lack of optimal use of electronic management applications. ${ }^{[17]}$ The reasons for such a lack were found out to be outdated software, modest electronic networks with lack of training programs, and the presence of threats and breakthroughs in technology, which led to poor acceptance of dealing with the Internet and consequently lack of health awareness. The study recommended the optimal use of electronic management applications in order to benefit from the technologies provided by the state. It also referred to the necessity of enhancing the Internet knowledge and strengthening digital software to prevent threats and intrusions. In addition, it pointed out the need for quality education outcomes under a health security system with effective management.

A deep understanding of the problem of data unavailability was recognized in a study which aimed to design an electronic medical record that contains a central database, which follows the system of the Federal Ministry of Health so that it can be accessed via the Internet and it links all hospitals in Sudan. ${ }^{[18]}$ In such a way data can be exchanged among different hospitals, which contributes to a better health care 
for patients. The main objective of this project was to create a central disease record, maintain medical records, and link the medical record to the national number, which will help raise the level of medical services in the country. The conclusion was that hospitals viewed the patient's medical record through a website available to all hospitals in Sudan.

The current study aims to have a database that pass countries' borders and has a positive impact on the satisfaction of the patients as it makes it very easy for them to reach their data and records anytime and anywhere on earth. Besides, the medical services will be much better on many levels such as the hospital, doctors, technicians, workers, etc. The users of the comprehensive database may exceed the patients to local and international authorities as the data provided will be more than a medical record that may be of an indispensable use specially during hard times of pandemics such as today. In addition, security authorities may find the data included very helpful in solving some of the mysterious incidents or the like.

\section{Methods}

The current study procedures employ the analytical descriptive and applied approaches because they are the most appropriate methods for studying this phenomenon and they are the most common methods in the study of human and social sciences. A questionnaire of 43 Likert scale questions was designed and distributed to the sample of the research. Then data were collected, defined, and analyzed to reach the findings and recommendations for the subject of research.

\subsection{Study population}

141 participants, 84 male and 57 female voluntarily took part in the study in 19 small hospitals operating in the western region.

\subsection{Sampling and data dollection}

A random sample of 171 questionnaires were distributed to patients, owners and employees of 19 small private hospitals in the western region. Only 141 questionnaires were collected. 84 male and 57 female participants voluntarily took part in the study.

\subsection{Study tools}

Questionnaires were designed in light of the research objectives and depended on developing and designing the questions as per previous studies and research questionnaires. An exploratory study was conducted and presented to some arbitrators in the College of Economics and Administration at King Abdulaziz University in order to ensure the face validity and the validity of the content, where the necessary modifications were made to the questionnaire. ${ }^{[19]}$

\subsection{Statistical analysis methods}

IBM SPSS software (version 25) has been employed in the statistical analysis of data. Statistical analyses, such as frequencies, percentages, Cronbach's alpha test, KolmogorovSmirnov and Shapiro-Wilk tests, Spearman's Rank Order Correlation (rho) have been used.

\section{Results}

\subsection{Instrumentation}

Data were gathered using a 43-item survey on a 5-point Likert scale, ranging from 5 (strongly agree) to 1 (strongly disagree). As many as two hundred and twenty copies of the questionnaire were distributed. However, only one hundred and seventy-three copies were collected. After revising the collected questionnaires and removing the incomplete ones, only 141 responses were analyzed with a $64 \%$ response rate. The collected data were coded, entered and processed using IBM SPSS Statistics version 25.

To make sure that the data set was error free before proceeding with data analysis, checks for outliers, i.e. values that are well below or above the other scores, were conducted. ${ }^{[20]} \mathrm{A}$ couple of data entry errors were identified and corrected. Statistical measures, such as descriptive analyses, frequencies, percentages, Cronbach's alpha test, Kolmogorov-Smirnov and Shapiro-Wilk tests, Spearman's Rank Order Correlation (rho) were conducted in order to achieve the objectives of the research.

\subsection{Participants}

Participants of the study were $(n=141)$. Of the 141 respondents, $59.6 \%$ (84) were males and $40.4 \%$ (57) were females. Regarding their age, their classification was as follows: 104 $(73.8 \%)$ were less than 30 years old; 15 (10.6\%) were 31 to 40 years old; $10(7.1 \%)$ were 41 to 50 years old and 12 $(8.5 \%)$ were 51 to 60 years old.

As depicted in Figure 1 below, the overwhelming majority of the informants (66\%) were bachelor's degree holders; followed by $36 \%$ who had post graduate degrees and finally $6 \%$ completed the basic education level.

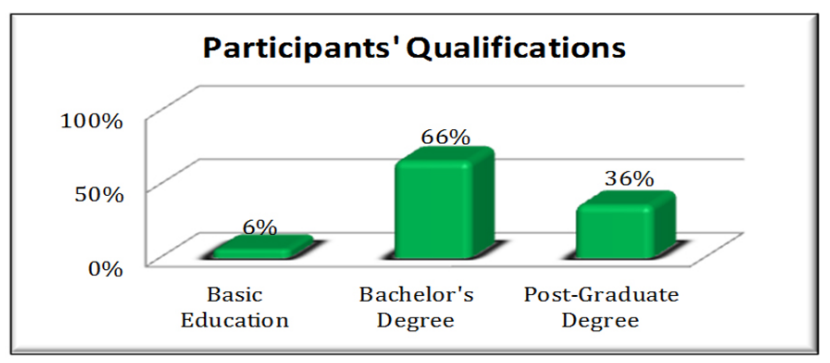

Figure 1. Participants' educational qualifications 
As seen in Figure 2 below, the vast majority (61\%) had less than five years of work experience; $12 \%$ were in the second category 6 to 10 years, $11 \%$ had 11 to 20 years, $9 \%$ had 21 to 30 years, and finally $4 \%$ had 31 to 40 years of experience.

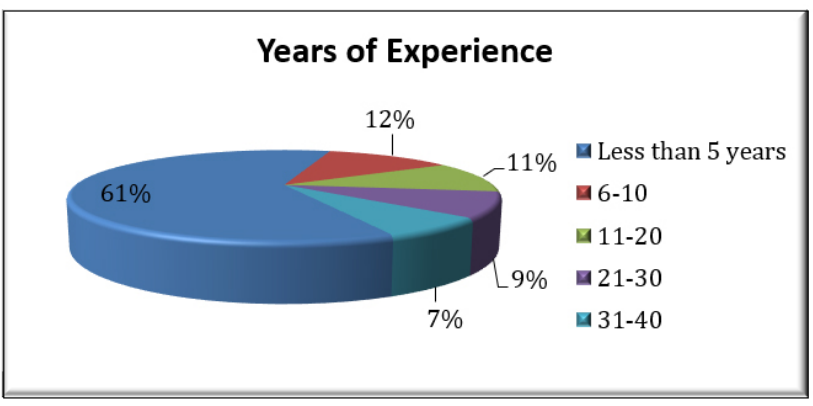

Figure 2. Participants' work experience profile

\subsection{Reliability of data collection instrument}

Due to the fact that the research instrument has been constructed by the researcher specifically for this study, the reliability of the questionnaire needed to be examined. By doing so, the instrument is said to be free from random error. It is illustrated that internal consistency is usually employed in order to examine a given scale's reliability. ${ }^{[21]}$ Table 1 below highlights the Cronbach's Alpha Coefficient for the questionnaire as a whole. Analysis indicated a high level of consistency amongst the participants' responses as values above .7 are deemed acceptable, but values more than .8 are favourable. ${ }^{[22]}$

Therefore, Cronbach's Alpha Coefficient analysis of the nine domains in the survey was carried out. Table 2 below highlights the Cronbach's Alpha Coefficient for each subscale.

\subsection{Normality and correlation tests}

To determine the appropriate correlation statistical type of analysis, both Kolmogorov-Smirnov and Shapiro-Wilk tests were utilised to check for the normality of distribution for each of the nine domains that constitute the research instrument. Table 3 below shows that all the nine domains were not normally distributed at $p<.05$, which is common in this case of such a quite large sample. As a result, the non-parametric statistic test, Spearman's Rank Order Correlation (rho), was conducted in order to examine the relationship between each domain from one side and improving the quality of services in small hospitals, achieving patient satisfaction and achieving local and international bodies' satisfaction on the other side.

Table 1. Cronbach's alpha reliability statistics

\begin{tabular}{lll}
\hline Cronbach's Alpha & Cronbach's Alpha Based on Standardized Items & Number of Items \\
\hline .884 & .894 & 43 \\
\hline
\end{tabular}

Table 2. Cronbach's alpha coefficients for the nine domains of the instrument

\begin{tabular}{|c|c|c|c|c|}
\hline No & Domain & Items & $\begin{array}{l}\text { Number of } \\
\text { Items }\end{array}$ & $\begin{array}{l}\text { Cronbach's } \\
\text { Alpha }\end{array}$ \\
\hline 1 & Quality of medical services & $4,10,26,30,36,40 \& 41$ & 7 & .81 \\
\hline 3 & Availability of patient medical data in and out of Saudi Arabia & $5,38 \& 39$ & 3 & .84 \\
\hline 4 & $\begin{array}{l}\text { Reduction of international treatment costs, which contributes to achieving } \\
\text { patient satisfaction }\end{array}$ & $9,16,19,21 \& 32$ & 5 & .91 \\
\hline 5 & Patient awareness of their legal rights & $6,11 \& 17$ & 3 & .93 \\
\hline 6 & Observing doctors' performance and minimizing errors & $7,8,31 \& 35$ & 4 & .85 \\
\hline 7 & $\begin{array}{l}\text { Enhancing local doctors' and hospitals' performance because of international } \\
\text { competition }\end{array}$ & $15,27,33 \& 34$ & 4 & .84 \\
\hline 8 & Security of elderly medical files & $18,20,23,24,25 \& 28$ & 6 & .89 \\
\hline 9 & Linking patient data with official bodies & $14,22,29,37,42 \& 43$ & 6 & .79 \\
\hline
\end{tabular}

Cohen ${ }^{[23]}$ outlines the rules for interpreting the correlation values: from .10 to .29 indicates a small correlation; from .30 to .49 indicates a medium correlation; and from .50 to 1.0 indicates a large correlation. Table 4 below exhibits the values of Spearman's Rho (rs) for the nine domains of the questionnaire. These values reveal that there are strong positive correlations between using a comprehensive international electronic medical file and (1) improving the quality of services in small hospitals, (2) achieving patient satisfaction and (3) achieving satisfaction level among local and international official bodies. 
Table 3. Tests of normality

\begin{tabular}{lllll}
\hline No & Domain & Items & $\begin{array}{l}\text { Kolmogorov- } \\
\text { Smirnov }\end{array}$ & Shapiro-Wilk \\
\hline 1 & Quality of medical services & $4,10,26,30,36,40 \& 41$ & .000 & .002 \\
2 & Readiness, speed \& confidentiality of patient data & $1,2,3,12 \& 13$ & .000 & .000 \\
3 & Availability of patient medical data in and out of Saudi Arabia & $5,38 \& 39$ & .000 & .000 \\
4 & $\begin{array}{l}\text { Reduction of international treatment costs, which contributes to } \\
\text { achieving patient satisfaction }\end{array}$ & $9,16,19,21 \& 32$ & .000 & .000 \\
5 & Patient awareness of their legal rights & $6,11 \& 17$ & .000 & .000 \\
6 & Observing doctors' performance and minimizing errors & $7,8,31 \& 35$ & .000 & .000 \\
7 & $\begin{array}{l}\text { Enhancing local doctors' and hospitals' performance because of } \\
\text { international competition }\end{array}$ & $15,27,33 \& 34$ & .000 & .000 \\
9 & Security of elderly medical files & $18,20,23,24,25 \& 28$ & .003 & .000 \\
\hline
\end{tabular}

Table 4. Spearman's rho coefficient values (rs) for the survey domains

\begin{tabular}{|c|c|c|c|}
\hline No & Domain & Items & $\begin{array}{l}\text { Spearman's Rho } \\
\text { Coefficient Values }\end{array}$ \\
\hline 1 & Quality of medical services & $4,10,26,30,36,40 \& 41$ & $0.626^{* *}$ \\
\hline 2 & Readiness, speed \& confidentiality of patient data & $1,2,3,12 \& 13$ & $0.620^{* *}$ \\
\hline 3 & Availability of patient medical data in and out of Saudi Arabia & $5,38 \& 39$ & $0.622^{* * *}$ \\
\hline 4 & $\begin{array}{l}\text { Reduction of international treatment costs, which contributes to achieving patient } \\
\text { satisfaction }\end{array}$ & $9,16,19,21 \& 32$ & $0.701^{* * *}$ \\
\hline 5 & Patient awareness of their legal rights & $6,11 \& 17$ & $0.617^{* * *}$ \\
\hline 6 & Observing doctors' performance and minimising errors & $7,8,31 \& 35$ & $0.629^{* * *}$ \\
\hline 7 & $\begin{array}{l}\text { Enhancing local doctors' and hospitals' performance because of international } \\
\text { competition }\end{array}$ & $15,27,33 \& 34$ & $0.579^{* *}$ \\
\hline 8 & Security of elderly medical files & $18,20,23,24,25 \& 28$ & $0.691^{* *}$ \\
\hline 9 & Linking patient data with official bodies & $14,22,29,37,42 \& 43$ & $0.627^{* *}$ \\
\hline
\end{tabular}

From the data presented in Table 4 above, a number of findings can be reached. First, the first hypothesis is accepted because there is a strong positive correlation (rs 0.626 ) between using a comprehensive electronic medical file and enhancing the quality of medical services which in turn would lead to increasing the level of patient satisfaction. In addition, the second hypothesis is also supported as there is a strong positive correlation ( $r$ 0.620) between implementing the idea of the electronic medical file and the readiness, speed and confidentiality of the information provided to the patient. Put it another way, participants believe that using the electronic medical file would make patient data more ready, confidential and accessible to the concerned personnel. As a result, this would lead to improving the quality of medical services and patient satisfaction.

In a similar manner, the third hypothesis is supported as well due to the fact that there is a strong positive correlation (rs 0.622 ) between putting the comprehensive electronic medical file into practice and the availability of patient medical information for doctors inside and outside the Kingdom. By so doing, patient data and medical reports and history can be accessed and updated wherever they are. Hence, this could improve the level of satisfaction among patient, local and international official bodies.

In the same vein, the fourth hypothesis is also approved due to the strong positive correlation (rs 0.701) between the availability of the electronic medical file and the reduction of treatment costs in case the patient seeks treatment internationally, which contributes to achieving patient satisfaction. Therefore, it can be concluded that the more the patient is able to get a national and international good medical service at a reasonable price, the more satisfied the patient is.

Similarly, the fifth hypothesis is supported due to the strong positive correlation (rs 0.617 ) between utilising the electronic medical file and increasing patients' awareness of their legal rights. Using the e-file would help the patient be fully aware of their medical history, prescribed medicines, previous op- 
erations, making complaints procedures, the way of paying medical costs safely, etc. This would contribute to improving the level of service and stimulating competition.

Furthermore, the sixth hypothesis is also correct because a strong positive correlation (rs 0.629) has been found between implementing the electronic medical file and increasing the ability of monitoring doctors' performance and minimising their errors. Consequently, it would be easier to observe doctors and hold them accountable for their practice.

In addition, the seventh hypothesis is also accepted as a strong positive correlation (rs 0.579 ) has been found between using electronic medical file and enhancing the performance of doctors and hospitals in Saudi Arabia due to the intense international competition. Therefore, doctors and hospitals in the kingdom have to face up the challenges of global competition. This in turn would increase the quality of medical services and improve the level of patient satisfaction.

Additionally, findings reveal that the eighth hypothesis is also supported due to the strong positive correlation (rs 0.691) between using the electronic medical file and increasing the level of security of elderly patients' medical files. This would necessitate educating employees about various information security laws in order to stay in line with the accelerated pace of the industry of information protection systems and programmes.

Finally, the ninth hypothesis is also accepted due to the strong positive correlation (rs 0.627 ) between using the electronic medical file and linking patient data with concerned official bodies. Participants believe that the electronic file helps link patient data with official authorities such as the Ministry of Health, the Ministry of Finance, the Pension Authority, the Ministry of Interior and Traffic Accident Authority, embassies and others. Therefore, such official authorities would be more able to monitor services and prices in hospitals as well as patient rights. In addition, the e-file may contribute to knowing all the latest information about the hospital, such as appointment of new doctors, opportunities for development and expansion of the hospital, vacancies, the rank of the hospital among other hospitals, as well as in the evaluation of its medical services.

In conclusion, results of the present study demonstrate that the Saudi people seem to believe that the significance of implementing the comprehensive electronic medical file is threefold. First, the quality of the medical services they receive would be developed whether inside Saudi Arabia or abroad. Second, patient satisfaction can be achieved as a consequence. Third, all the concerned official authorities would be more able to do their jobs as they will be provided with the needed data about the patients in a timely and organised manner.

Here are two obvious examples that the participants mentioned concerning improving the quality of the medical services. The e-file can offer a practical mechanism for observing and monitoring doctors' performance which would lead to minimizing their errors. An additional advantage of using the e-file is that doctors and hospitals operating inside Saudi Arabia would be pushed to their limit to improve their performance in order for them to cope with the internationally increasing competition.

With reference to patient satisfaction, informants stated that using the e-file would make them more satisfied with the services they get. That is because their medical records would be more ready for the concerned personnel only, hence more secure. Furthermore, costs of treatment can be reduced significantly in case they decide to seek treatment overseas. Additionally, they would be more aware of their rights in general and their legal rights in particular.

Finally, participants contended that using the e-file would facilitate linking their data with the concerned official bodies. Thus, these organisations would be more able to function more efficiently. Besides, they would be more capable of having a closer eye on hospitals.

\section{RECOMMENDATIONS}

(1) Spreading electronic education and medical awareness among patients and doctors. ${ }^{[11]}$

(2) Training of all medical personnel on the importance of patient rights and methods of dealing with them and on the necessity of applying medical ethics and medical charter so that no doctor works without training.

(3) Raising the level of education in medical, technical and computer field of work. ${ }^{[24]}$

(4) Developing the skills of medical field staff and applying the concepts of the comprehensive international electronic medical file and professional standards. ${ }^{[25]}$

(5) Establishing disciplinary measures in the event that medical personnel do not comply with confidentiality standards or fail to protect the patient's data verbally or in writing or in the event of unwillingness of doctors or medical personnel to abide by the followed regulations.

(6) Encouraging hospitals' administrations to appoint a highly educated and highly qualified officials to monitor the progress of electronic files.

(7) Promoting the administration's belief in the importance of the comprehensive international medical file, the participation of patients, doctors, and concerned parties, their opinions, complaints, and demands, and the use of their intel- 
lectual efforts to reach the best and latest ways of developing it. ${ }^{[26]}$

(8) Communicating with local, regional and international bodies to find out the best ways to improve the performance of the comprehensive international medical file and to reduce medical errors and financial exploitation of patients. ${ }^{[27]}$

(9) Benefiting from research in this medical field and from specialized international hospitals, applying the principle of prediction, future studies, and studying the causes of medical errors. ${ }^{[28]}$

(10) Introducing the right of the patient to view his medical file, and his family right to review his medical file after his death, to know the causes of death, and to consult others in the event of medical errors, and even the patient and his family members should have access to the DNA. Reviewing such data may lead to refunding the treatment money in the event the patient is dissatisfied with the method of examination or even the way the doctor handles his case.

(11) Doing periodic medical reports and adopting a method of follow-up and reporting in the event of any medical error. (12) Striving to take advantage of modern technology, especially mobile devices, so that there is a permanent contact between the patient and the hospital. This may be achieved via the establishment of a special hospital mobile phone application that enables the patient to contact the doctor, the administration of the hospital and the authorities in the event of complaints about the doctor's ethics, the poor service provided by the hospital, the exploitation of the patient financially, giving the patient inappropriate medicines or in the case of medical errors. In fact, the electronic medical file can show every tiny details in the doctor's dealings with the patient.

(13) Urging doctors and hospital administration to record all the patient's related matters in the medical file, including the medicines that were dispensed, medical examinations and the costs of treatment.

(14) Maintaining the confidentiality of patients' information, preventing them from being modified or concealed by the doctor or medical personnel. Providing the patient an access to such information and preventing not authorized people from reaching it and protecting the patient's health and creat- ing an appropriate healthy environment.

(15) Ensuring the e-file contains biometrics such as the eye print, palm print, face print, finger print and DNA, as this may contribute to the identification of the deceased, especially in cases of fires, floods, drowning, etc.

(16) Linking the school and university medical file to all age groups from primary, middle and secondary schools to university students with the comprehensive e-medical file. ${ }^{[29]}$ (17) Establishing an entity to assist patients by reviewing examinations and the patient's medical record so that the doctor can dispense medicines electronically, especially in recurrent diseases that are easy to treat. This may reduce pressure on doctors and decrease waiting hours for good doctors instead of having to visit any other doctor without enough experience.

(18) Finally, conducting more research on the e-medical file and the comprehensive international profile in order to reach deeper and more comprehensive results to assess the level of doctors' performance, know what the causes of medical errors are, improve the quality of performance and patient satisfaction, and study them from all aspects of age, personality, educational qualification, experience, income and the required financial costs. Research is preferably to be done on the e-medical file for women in particular, as research is almost rare in this area.

\section{Limitations}

The study was based on the western region in the city of Jeddah which it is the first commercial center in the Kingdom of Saudi Arabia but it is recommended that the geographical coverage to be wider for the results to reflect even more and its reliability to increase so more studies in other areas are needed. The questionnaire is recommended to be a bit shorter and participants are to be offered incentives in order to fight against lack of interest in the research. Some of the participants even refused to participate either for fear of taking responsibility or for unwillingness to cooperate.

\section{CONFlicts of InTERest Disclosure}

The authors declare they have no conflicts of interest.

\section{REFERENCES}

[1] Sreenivas T, Prasad G. Patient Satisfaction - A Comparative Study. Journal of the Academy of Hospital Administration. 2003; 2: 19.

[2] Fraser H, Biondich P, Moodley D, et al. Implementing electronic medical records in developing countries. The Journal of Innovation in Health Informatics. 2005; 13(2): 83-95. PMid: 15992493. https://doi.org/10.14236/jhi.v13i2.585
[3] Nahed M. Evaluation of the Quality of Health Services Provided by Private Hospitals. Scientific Journal of Economics and Trade. 1999; 3(1): 28-45.

[4] Alberti K. Medical errors: a common problem: It is time to get serious about them. BMJ British Medical Journal. 2001. PMid: 11230049. https://doi.org/10.1136/bmj .322.7285.501

[5] Abdul Hakim A. The flood of counterfeit medications is a threat to 
the world. Alittihad Newspaper. 2006 Aug 13.

[6] World Health Organization (WHO). Bulletin of the World Health Organization. 2021; 88; 624-631. PMid: 20680128. https ://doi . org/10.2471/BLT.08.056879

[7] Holmes N, Lingard H, Yesilyurt Z, et al. An Exploratory Study of Meanings of Risk Control for Long Term and Acute Effect Occupational Health and Safety Risks in Small Business Construction Firms. Journal of Safety Research. 1999; 30(4): 251-261. https ://doi.org/10.1016/S0022-4375(99)00020-1

[8] Wikipedia - Black Fungus. Available from: https://en.wikiped ia.org/wiki/Black_fungus

[9] Al-Jarusheh Y. An association for the care of the elderly in Mecca Al-Mukarramah. Alriyadh Newspaper, Saudi Arabia. 2010 Apr 6. Available from: https://www.alriyadh.com/513735

[10] Ali T, Nagwa S. Safety systems and occupational health in small businesses. Asyut Journal of Environmental Studies. 2012; 36: 99-119.

[11] Nassef TM, Haggag A, Nessim S, et al. A Dynamic Network Approach for E-Learning Based Electronics Virtual Lab to Mitigate COVID-19. 2020.

[12] Al-Shehri S. Activating information systems to enhance human security in the health strategy of the Kingdom of Saudi Arabia [master's thesis]. [Riyadh, Kingdom of Saudi Arabia]: Faculty of Strategic Sciences, Naif Arab University for Security Sciences; 2013.

[13] Mostafa N, Rasha M, Safaa H. Quality of documentation of electronic medical information systems at primary health care units in Alexandria, Egypt. East Mediterranean Health Journal. 2014; 2(20): 105-111. PMid: 24945559. https://doi.org/10.26719/2014. 20.2. 105

[14] Al-Qassem N. The role of electronic administration in the administrative development of the medical services management [master's thesis]. [Riyadh, Kingdom of Saudi Arabia]: Faculty of Strategic Sciences, Naif Arab University for Security Sciences; 2016.

[15] Al-Sudairi B. The role of the departments of communication and information security in dealing with the breaches in military hospital systems [master's thesis]. [Riyadh, Kingdom of Saudi Arabia]: Faculty of Strategic Sciences, Naif Arab University for Security Sciences; 2017.

[16] Al-Sulami HA. A national model for automating and controlling health information in hospitals in the Kingdom of Saudi Arabia. Conferences of Arts, Humanities and Natural Sciences. Istanbul, Turkey;
2019 Aug. 25-26 p. https://doi.org/10.24897/acn.64.68.4 38

[17] Al-Waala M. The role of electronic management in enhancing health security: King Faisal Hospital: A case study [master's thesis]. [Riyadh, Kingdom of Saudi Arabia]: Faculty of Strategic Sciences, Naif Arab University for Security Sciences; 2018.

[18] Yaqoub TM, Taha RM, Othman RB, et al. Designing a system for keeping patient records in hospitals [doctoral thesis]. [Sudan]: Faculty of Computer Science and Information Technology, Sudan University of Science and Technology; 2020.

[19] Uma S, Bougie R. Research methods for business: A skill building approach. John Wiley \& Sons; 2016.

[20] Crowder MJ. Statistical analysis of reliability data. Routledge; 2017. https://doi.org/10.1201/9780203738726

[21] Taber KS. The use of Cronbach's alpha when developing and reporting research instruments in science education. Research in Science Education. 2018; 48(6): 1273-1296. https ://doi.org/10.1007/ s11165-016-9602-2

[22] Pallant J. SPSS survival manual: A step by step guide to data analysis using IBM SPSS. Routledge; 2020. https : //doi .org/10.4324/ 9781003117445

[23] Cohen J. Statistical power analysis for the behavioral sciences. Academic Press; 2013. https ://doi.org/10.4324/978020377158 7

[24] Al-Zubaidi A. Medicine is science, experience, ethics, humility and honesty. Alriyadh Newspaper, Saudi Arabia. 2018 Mar 21. Available from: https://www .alriyadh. com/1670044

[25] International Health Organization. Basic health technologies: Report from the Secretariat. Session No. 118. 2006.

[26] Al-Khawlani KA. E-training and its Role in Developing Electronic Management Systems in the General Administration of Medical Services for the Armed Forces [master's thesis]. [Riyadh, Kingdom of Saudi Arabia]: Faculty of Administrative Sciences, Naif Arab University for Security Sciences; 2017.

[27] Janahi NA. Are you a doctor or a trader? Alwatan Newspaper. Riyadh, Saudi Arabia. 2017 Feb 11.

[28] Fahmi W. What is health information system (HIS)? And how does it work? Almowaten Newspaper, Saudi Arabia. 2017 Oct 31.

[29] Al-Zoubi M. The level of implementing the electronic management in public schools. Aldara Journal for Research and Studies. 2014; 21(1): 53-96 